\title{
Diabetes mellitus and the risk of glioma: a meta-analysis
}

\author{
Luqian Zhao ${ }^{1}$, Zhiping Zheng ${ }^{1}$, Ping Huang ${ }^{1}$ \\ ${ }^{1}$ Department of Geriatrics, Guangzhou First People's Hospital, Guangzhou Medical University, Guangzhou 510180, \\ Guangzhou, China \\ Correspondence to: Ping Huang, e-mail: gzhuangping@126.com \\ Keywords: diabetes, glioma, association, meta-analysis \\ Received: September 06, $2015 \quad$ Accepted: November 28, $2015 \quad$ Published: December 14, 2015
}

\section{ABSTRACT}

Some studies reported a statistically significant inverse association between diabetes mellitus (DM) and risk of gliomas. However, the result is still controversial. We thus did a meta-analysis and summarized the evidence on the incidence of gliomas that has been studied in its association with DM. Seven case-control studies and 4 cohort studies were selected in this meta-analysis $(n=5898251)$. DM was significantly associated with decreased risk of gliomas $(\mathrm{OR}=0.79 ; 95 \% \mathrm{CI} 0.67-0.93 ; P=0.004$; $I^{2}=59 \%$ ). In the subgroup analysis of race, Caucasians of DM showed decreased risk of gliomas (OR $=0.81 ; 95 \% \mathrm{CI} 0.69-0.94 ; P=0.007)$. In the subgroup analysis of design, a statistically significant protective effect of DM on gliomas was observed in case-control studies $(\mathrm{OR}=0.68 ; 95 \% \mathrm{CI}, 0.53-0.87 ; P=0.002)$, while no such effect was observed in cohort studies ( $O R=0.97 ; 95 \% \mathrm{CI}, 0.83-1.13 ; P=0.70)$. In a further stratified analysis by gender, a significant association was found among males with $D M(O R=0.83 ; 95 \% C I, 0.70-0.99 ; P=0.04)$. No significant association was found between females with $D M$ and gliomas (OR $=0.97 ; 95 \%$ CI, 0.78-1.21; $P=0.81$ ). In summary, this meta-analysis of current evidence suggests that $D M$ is significantly associated with decreased gliomas risk in Caucasian and males.

\section{INTRODUCTION}

Gliomas account for almost $80 \%$ of primary malignant brain tumors, and fewer than $50 \%$ of glioma patients live longer than 5 years after diagnosis [1]. Despite improvements in clinical care over the last 20 years, gliomas remain associated with considerable morbidity. To date, the only established environmental risk factor is exposure to moderate-to-high doses of ionizing radiation [2].

Diabetes mellitus (DM) is the most common endocrine disorder that affects 246 million people worldwide. The International Diabetes Federation (IDF) predicts that the number of people with DM will increase up to 380 million within twenty years [3]. Many studies suggest that DM is associated with an increased risk of cancer, such as liver, pancreas, endometrium, colorectum, breast, and bladder [4]. Recently, an umbrella review also found the significant associations between DM and risk of developing breast, cholangiocarcinoma (both intrahepatic and extrahepatic), colorectal, endometrial, and gallbladder cancer [5]. However, this study did not investigate the association between DM and risk of gliomas. Some studies reported a statistically significant inverse association between DM and risk of gliomas. However, the result is still controversial [6-16]. We thus did a meta-analysis and summarised the evidence on the incidence of gliomas that has been studied in its association with DM.

\section{RESULTS}

Characteristics of eligible studies

A total of 237 potential studies were identified by preliminary searching PubMed, Web of Science, Science Direct, EMBASE, and Cochrane Library databases, among which 7 case-control studies and 4 cohort studies were selected, involving a total of 5898251 subjects in this meta-analysis. The detailed literature search strategy was showed in Figure 1. The baseline characteristics, such as author name, publication year, ethnicity, design, age, gender, sample size, and covariants were depicted in Table 1 . The quality of the 11 studies was high.

Association of DM and risk of gliomas

As shown in Figure 2, DM was significantly associated with decreased risk of gliomas $(\mathrm{OR}=0.79$; 
95\% CI $0.67-0.93 ; P=0.004 ; I^{2}=59 \%$ ). In the subgroup analysis of race, Caucasians of DM showed decreased risk of gliomas $(\mathrm{OR}=0.81 ; 95 \%$ CI $0.69-0.94 ; P=0.007)$. In the subgroup analysis of design, a statistically significant protective effect of DM on gliomas was observed in case-control studies $(\mathrm{OR}=0.68 ; 95 \% \mathrm{CI}, 0.53-0.87$; $P=0.002)$, while no such effect was observed in cohort studies $(\mathrm{OR}=0.97 ; 95 \% \mathrm{CI}, 0.83-1.13 ; P=0.70)$. In a further stratified analysis by gender, a significant association was found among males with $\mathrm{DM}(\mathrm{OR}=0.83$; $95 \%$ CI, 0.70-0.99; $P=0.04)$. No significant association was found between females with DM and gliomas $(\mathrm{OR}=0.97 ; 95 \% \mathrm{CI}, 0.78-1.21 ; P=0.81)$. The results were showed in Table 2.

Sensitivity analysis was carried out repeatedly by precluding a single study at a time. The results demonstrated that the estimates before and after the deletion of each study were similar (Figure 3 ). No evidence of publication bias was found in this meta-analysis by funnel plot (Figure 4) and Egger's test $(P=0.24)$.

\section{DISCUSSION}

This is a comprehensive meta-analysis for clarification of the association between DM and risk of gliomas. Seven case-control studies and four cohort studies involving more than 580000 individuals were included in this study. The results suggested that DM was significantly associated with the decreased risk of gliomas. In the subgroup analysis by ethnicity, we noted that Caucasians with DM had decreased gliomas risk. However, there is no studies of Asians and other races. Although the pooled analysis from the case-control studies suggested a significant reduction in gliomas risk, the results from the cohort studies were non-significant, suggesting that our conclusion depend mainly on the casecontrol studies. It is generally thought that cohort studies provide stronger evidence regarding an association than case-control studies because they are less prone to recall or selection bias. In the subgroup analysis by gender, the inverse association between DM and gliomas was more apparent in men than women. Gender-specific hormonal changes in diabetic patients could serve as a possible explanation.

Previous studies suggested that DM might be a prognostic factor for cancers. Song et al. suggests that long-term DM is associated with an increased risk of pancreatic cancer [17]. Luo et al. found that DM was associated with an increased risk of colorectal neoplasia and adenoma [18]. Zhu et al. indicated that men with diabetes have a modestly increased risk of bladder cancer, while women with diabetes were not the case [19]. Chen and coworkers revealed that there was a significant negative impact of DM on overall survival

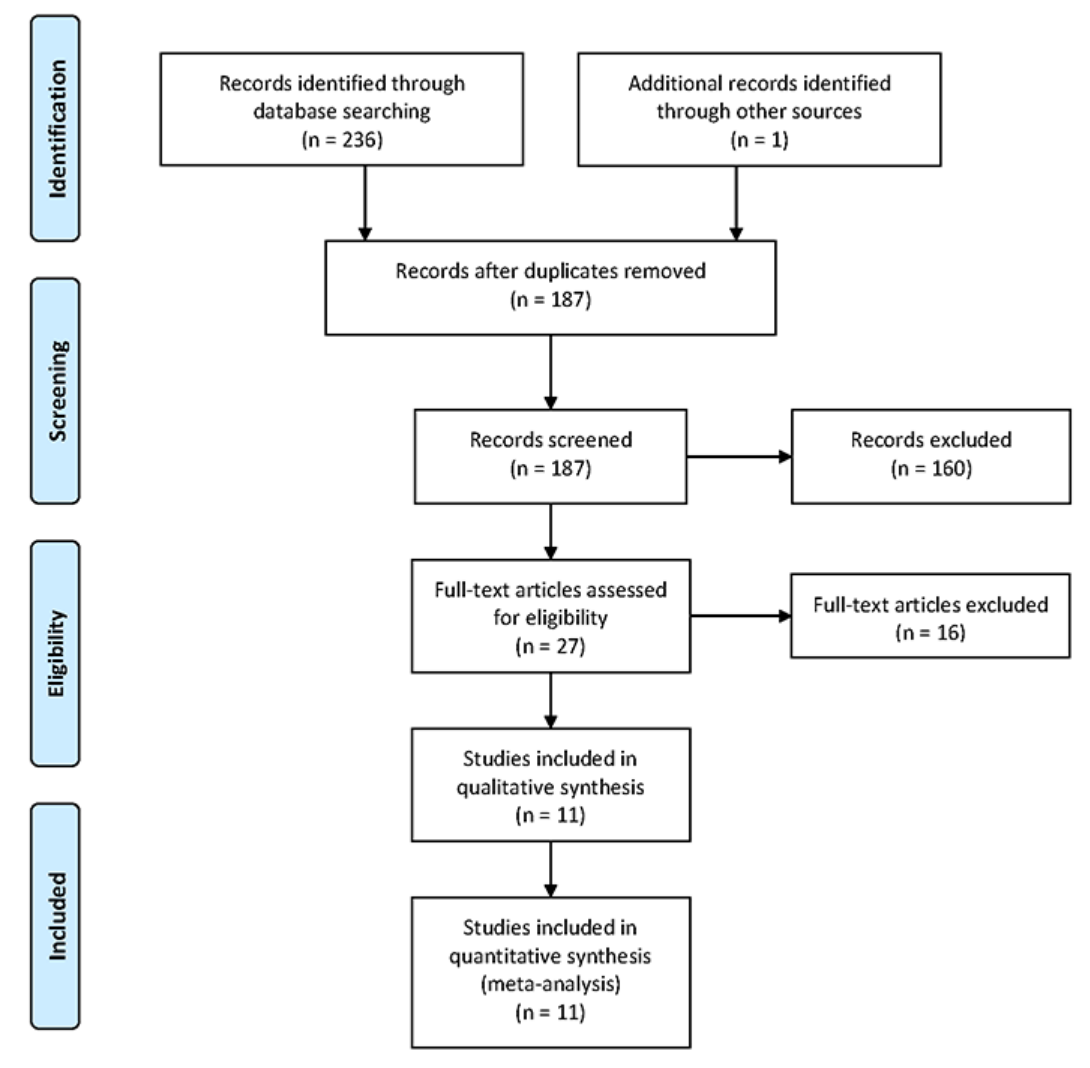

Figure 1: The selection of included studies. 
Table 1: Characteristics of the included studies

\begin{tabular}{|c|c|c|c|c|c|c|c|c|c|}
\hline First author & Year & $\begin{array}{l}\text { Study } \\
\text { design }\end{array}$ & Race & Age & $\begin{array}{c}\text { Male } \\
(\%)\end{array}$ & $\begin{array}{l}\text { Sample } \\
\text { size }\end{array}$ & $\begin{array}{c}\text { Type of } \\
\text { Diabetes }\end{array}$ & Covariant & $\begin{array}{c}\text { NOS } \\
\text { scores }\end{array}$ \\
\hline Cicuttini & 1997 & $\begin{array}{l}\text { Case- } \\
\text { control }\end{array}$ & Caucasian & 48.9 & 60 & 838 & NA & Age and sex & 8 \\
\hline Wideroff & 1997 & Cohort & Caucasian & 64 & 50 & 109581 & Mixed & NA & 7 \\
\hline Schlehofer & 1999 & $\begin{array}{l}\text { Case- } \\
\text { control }\end{array}$ & Caucasian & $20-80$ & 54 & 3165 & NA & Age and sex & 8 \\
\hline Brenner & 2002 & $\begin{array}{l}\text { Case- } \\
\text { control }\end{array}$ & Mixed & $18-90$ & 57 & 1288 & NA & $\begin{array}{l}\text { Age, sex, } \\
\text { race or } \\
\text { ethnicity and } \\
\text { distance of } \\
\text { residence } \\
\text { from hospital }\end{array}$ & 8 \\
\hline Schwartzbaum & 2005 & $\begin{array}{l}\text { Case- } \\
\text { control }\end{array}$ & Caucasian & 69 & 56 & 143573 & NA & $\begin{array}{c}\text { Age, sex, } \\
\text { and year of } \\
\text { diagnosis }\end{array}$ & 8 \\
\hline Swerdlow & 2005 & Cohort & Caucasian & $0-49$ & 54 & 28900 & I and II & NA & 7 \\
\hline Stocks & 2009 & Cohort & Caucasian & 44.8 & 61 & 30285 & NA & $\begin{array}{l}\text { Smoking, } \\
\text { body mass } \\
\text { index }\end{array}$ & 8 \\
\hline Campbell & 2012 & Cohort & Mixed & $>30$ & 44 & 1053831 & NA & $\begin{array}{c}\text { Age, } \\
\text { education, } \\
\text { body mass } \\
\text { index, } \\
\text { smoking, } \\
\text { alcohol } \\
\text { intake, } \\
\text { vegetable } \\
\text { intake, red } \\
\text { meat intake, } \\
\text { physical } \\
\text { activity, and } \\
\text { aspirin use }\end{array}$ & 9 \\
\hline Kitahara & 2014 & $\begin{array}{l}\text { Case- } \\
\text { control }\end{array}$ & Mixed & 57 & 52 & 3157 & NA & Age, sex & 8 \\
\hline Cahoon & 2014 & $\begin{array}{l}\text { Case- } \\
\text { control }\end{array}$ & Mixed & 52 & 100 & 4501578 & NA & $\begin{array}{c}\text { Age } \\
\text { category, } \\
\text { calendar } \\
\text { time, race, } \\
\text { and number } \\
\text { of hospital } \\
\text { visits. }\end{array}$ & 9 \\
\hline Seliger & 2015 & $\begin{array}{l}\text { Case- } \\
\text { control }\end{array}$ & Caucasian & 55.5 & 55 & 22055 & NA & $\begin{array}{c}\text { Age, sex, } \\
\text { calendar } \\
\text { time, general } \\
\text { practice }\end{array}$ & 8 \\
\hline
\end{tabular}

NA, not available; NOS, Newcastle-Ottawa Scale. 
Table 2: Meta-analysis results and subgroup analyses

\begin{tabular}{|c|c|c|c|c|}
\hline & $I^{2}(\%)$ & Model & OR $(95 \% \mathrm{CI})$ & $P$ value \\
\hline Overall & 59 & $\mathrm{R}$ & $0.79(0.67-0.93)$ & 0.004 \\
\hline Caucasian & 22 & $\mathrm{~F}$ & $0.81(0.69-0.94)$ & 0.007 \\
\hline Case-control & 72 & $\mathrm{R}$ & $0.68(0.53-0.87)$ & 0.002 \\
\hline Cohort & 0 & $\mathrm{~F}$ & $0.97(0.83-1.13)$ & 0.70 \\
\hline Male & 70 & $\mathrm{R}$ & $0.83(0.70-0.99)$ & 0.04 \\
\hline Female & 48 & $\mathrm{~F}$ & $0.97(0.78-1.21)$ & 0.81 \\
\hline
\end{tabular}

F, fixed effects model; R, random effects model.

(OS), cancer-specific survival (CSS), and recurrence-free survival (RFS) in renal cell carcinoma patients [20]. Zhou and coworkers revealed that women with DM are at higher risk of breast cancer [21].

Several limitations of this study should be noted. Firstly, only published studies that were included in the selected electronic databases were identified; it is possible that some relevant published or unpublished studies may have been missed. Secondly, no studies with Asians and other races was included in this meta-analysis. Thirdly, marked heterogeneity of studies was seen in this study.
We attempted to find the exact factor that can account for the heterogeneity by subgroup analysis. Fortunately, the heterogeneity was decreased in the subgroup analysis of race. Fourthly, owing to the limited data in the included studies, we cannot analyze the associations between type $1 \mathrm{DM}$ or type $2 \mathrm{DM}$ and gliomas, separately. Finally, this study was meta-analysis of case-control study and cohort study. Confounding should be considered.

In summary, this meta-analysis of current evidence suggests that DM is significantly associated with decreased gliomas risk.
Study

ID

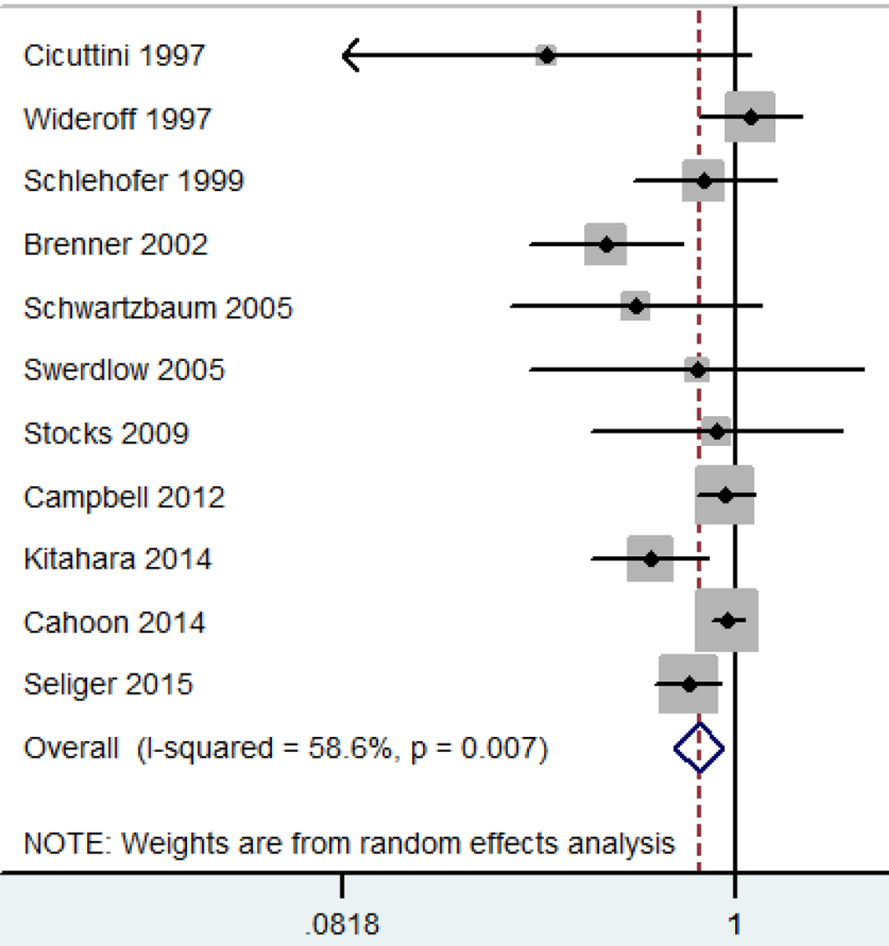

$\%$

OR $(95 \% \mathrm{Cl}) \quad$ Weight

\begin{tabular}{ll}
$0.30(0.08,1.10)$ & 1.43 \\
$1.10(0.80,1.51)$ & 11.72 \\
$0.82(0.52,1.29)$ & 7.92 \\
$0.44(0.27,0.72)$ & 7.23 \\
$0.53(0.24,1.17)$ & 3.46 \\
$0.78(0.27,2.25)$ & 2.08 \\
$0.89(0.40,1.98)$ & 3.41 \\
$0.94(0.78,1.13)$ & 16.80 \\
$0.58(0.40,0.84)$ & 10.05 \\
$0.95(0.86,1.05)$ & 20.04 \\
\hline $0.74(0.60,0.91)$ & 15.86 \\
\hline $0.79(0.67,0.93)$ & 100.00 \\
\hline
\end{tabular}

Figure 2: Meta-analysis of the association between DM and risk of gliomas. 


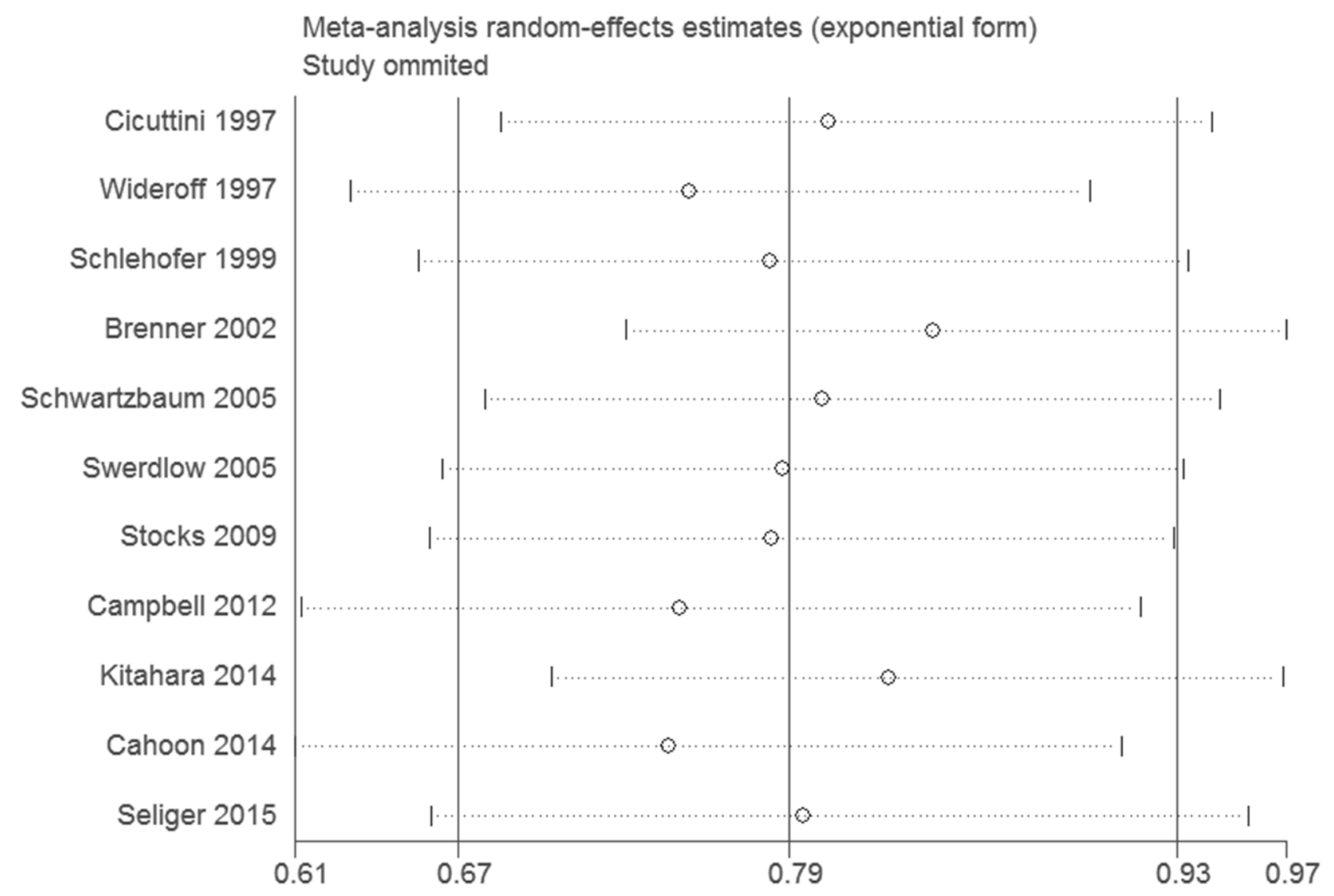

Figure 3: Sensitivity analysis of the association between DM and risk of gliomas.

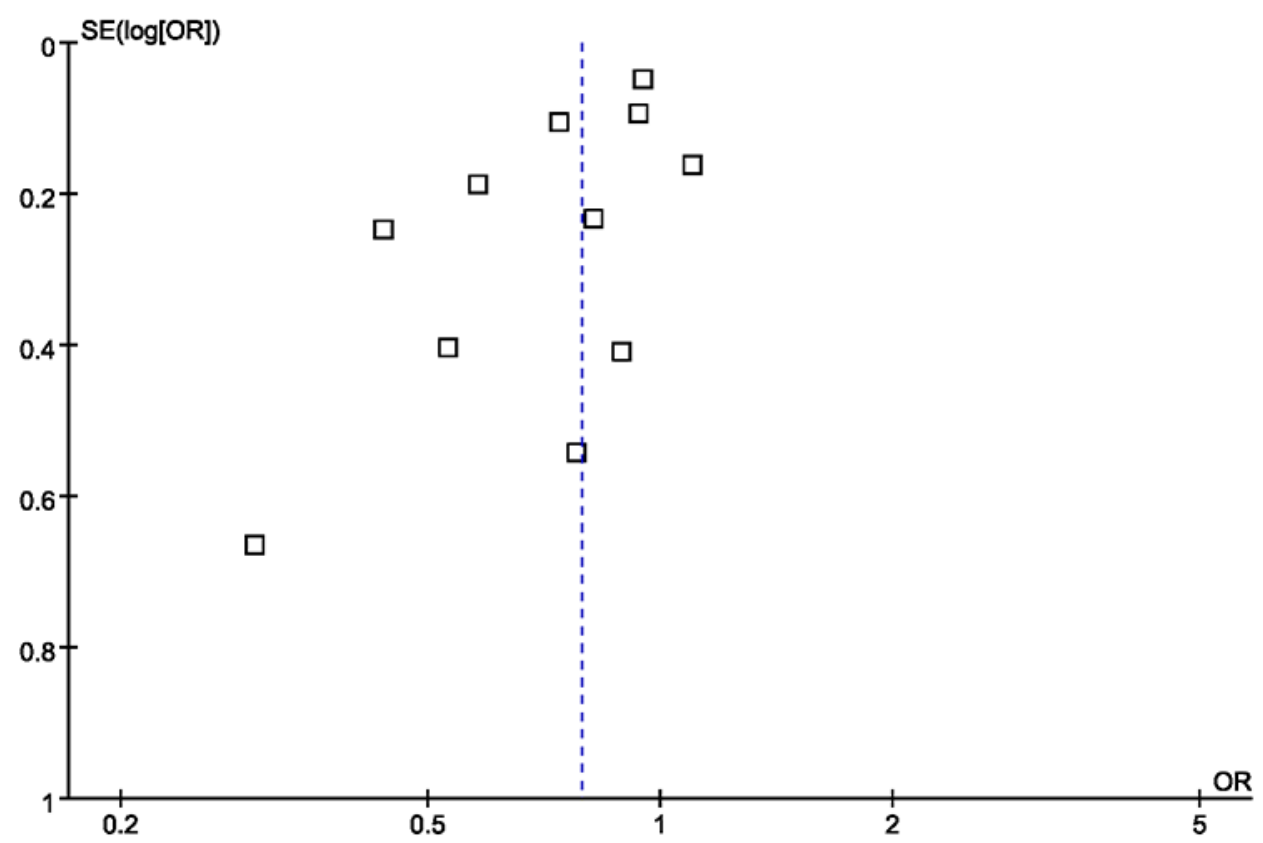

Figure 4: Funnel plot of the association between DM and risk of gliomas. 


\section{MATERIALS AND METHODS}

\section{Publication search}

A systematic search was conducted in the PubMed, Web of Science, Science Direct, EMBASE, and Cochrane Library databases until Aug 16, 2015, with no limits. The search strategies were based on combinations of the following keywords: Gliomas, brain tumor, Diabetes mellitus, Diabetes, DM. The MeSH terms were glioma and diabetes mellitus. In addition, we checked relevant reviews on the topic of interest. We traced the reference lists of selected articles and used Google Scholar to find potential studies.

\section{Study selection}

Studies were included in the meta-analysis if they fulfilled the following inclusion criteria: 1) study design: case-control or cohort studies; 2) population: DM patients; 3) primary outcome: the effect of DM on the risk of gliomas. Studies were included in the meta-analysis if they presented estimates of the OR or relative risk (RR) and the corresponding $\mathrm{CI}$ on the association between DM and risk of gliomas. When multiple reports were published on the same study population, we included the study with the largest number of cases. Abstract, case reports, review articles, experimental studies and commentary articles were excluded.

\section{Data extraction and qualitative assessment}

Two investigators extracted data from the included studies independently, and the respective studies were retrieved for further consideration if judged pertinent by one or two reviewers. Any discrepancies were identified and resolved by consensus. For each study, the following data were extracted: first author's name, year of publication, study design, race, age, gender, sample size, and covariant. A modification of the Newcastle-Ottawa Scale (NOS) was used as an assessment tool for selection, comparability, and outcome assessment.

\section{Statistical analysis}

OR and $95 \%$ CI were employed to evaluate the strength of the association between DM and risk of gliomas. The $\mathrm{I}^{2}$ statistic were used to assess the degree of heterogeneity among the studies included in the meta-analysis. If heterogeneity was observed among the studies $\left(\mathrm{I}^{2}>50 \%\right)$, the random-effects model was used to estimate the pooled OR (the DerSimonian and Laird method). Otherwise, the fixed-effects model was adopted (the Mantel-Haenszel method). Subgroup analyses were carried out by ethnicity, design, and gender. Sensitivity analysis was performed through sequentially excluded individual studies to assess the stability of the results.
The potential publication bias was examined visually in a funnel plot of $\log [\mathrm{OR}]$ against its standard error (SE), and the degree of asymmetry was tested using Egger's test. All statistical tests were performed using Revman 5.1 software (Nordic Cochrane Center, Copenhagen, Denmark) and STATA 11.0 software (Stata Corporation, College Station, TX, USA). A P value $<0.05$ was considered statistically significant.

\section{CONFLICTS OF INTEREST}

The authors declare no conflicts of interest.

\section{REFERENCES}

1. Kohler BA, Ward E, McCarthy BJ, Schymura MJ, Ries LA, Eheman C, Jemal A, Anderson RN, Ajani UA, Edwards BK. Annual report to the nation on the status of cancer, 1975-2007, featuring tumors of the brain and other nervous system. J Natl Cancer Inst. 2011;103:714-36.

2. Bondy ML, Scheurer ME, Malmer B, Barnholtz-Sloan JS, Davis FG, Il'yasova D, Kruchko C, McCarthy BJ, Rajaraman P, Schwartzbaum JA, Sadetzki S, Schlehofer B, Tihan T, Wiemels JL, Wrensch M, Buffler PA; Brain Tumor Epidemiology Consortium. Brain tumor epidemiology: consensus from the Brain Tumor Epidemiology Consortium. Cancer. 2008;113:1953-68.

3. International Diabetes Federation Diabetes Atlas, http:// www.eatlas.idf.org/prevalence/.

4. Giovannucci E, Harlan DM, Archer MC, Bergenstal RM, Gapstur SM, Habel LA, Pollak M, Regensteiner JG, Yee D. Diabetes and cancer: a consensus report. Diabetes Care. 2010;33:1674-85

5. Tsilidis KK, Kasimis JC, Lopez DS, Ntzani EE, Ioannidis JP. Type 2 diabetes and cancer: umbrella review of metaanalyses of observational studies. BMJ. 2015;350:g7607. doi: 10.1136/bmj.g7607.

6. Cicuttini FM, Hurley SF, Forbes A, Donnan GA, Salzberg M, Giles GG, McNeil JJ. Association of adult glioma with medical conditions, family and reproductive history. Int J Cancer. 1997;71:203-7.

7. Wideroff L, Gridley G, Mellemkjaer L, Chow WH, Linet M, Keehn S, Borch-Johnsen K, Olsen JH. Cancer incidence in a population-based cohort of patients hospitalized with diabetes mellitus in Denmark. J Natl Cancer Inst. 1997;89:1360-5.

8. Schlehofer B, Blettner M, Preston-Martin S, Niehoff D, Wahrendorf J, Arslan A, Ahlbom A, Choi WN, Giles GG, Howe GR, Little J, Ménégoz F, Ryan P. Role of medical history in brain tumour development. Results from the international adult brain tumour study. Int J Cancer. 1999;82:155-60.

9. Brenner AV, Linet MS, Fine HA, Shapiro WR, Selker RG, Black PM, Inskip PD. History of allergies and autoimmune 
diseases and risk of brain tumors in adults. Int $\mathrm{J}$ Cancer. 2002;99:252-9.

10. Schwartzbaum J, Jonsson F, Ahlbom A, Preston-Martin S, Malmer B, Lönn S, Söderberg K, Feychting M. Prior hospitalization for epilepsy, diabetes, and stroke and subsequent glioma and meningioma risk. Cancer Epidemiol Biomarkers Prev. 2005;14:643-50.

11. Swerdlow AJ, Laing SP, Qiao Z, Slater SD, Burden AC, Botha JL, Waugh NR, Morris AD, Gatling W, Gale EA, Patterson CC, Keen H. Cancer incidence and mortality in patients with insulin-treated diabetes: a UK cohort study. Br J Cancer. 2005;92:2070-5.

12. Stocks T, Rapp K, Bjørge T, Manjer J, Ulmer H, Selmer R, Lukanova A, Johansen D, Concin H, Tretli S, Hallmans G, Jonsson H, Stattin P. Blood glucose and risk of incident and fatal cancer in the metabolic syndrome and cancer project (me-can): analysis of six prospective cohorts. PLoS Med. 2009;6:e1000201.

13. Campbell PT, Newton CC, Patel AV, Jacobs EJ, Gapstur SM. Diabetes and cause-specific mortality in a prospective cohort of one million U.S. adults. Diabetes Care. 2012;35:1835-44.

14. Kitahara CM, Linet MS, Brenner AV, Wang SS, Melin BS, Wang Z, Inskip PD, Freeman LE, Braganza MZ, Carreón T, Feychting M, Gaziano JM, Peters U, Purdue MP, Ruder AM, Sesso HD, Shu XO, Waters MA, White E, Zheng W, Hoover RN, Fraumeni JF Jr, Chatterjee N, Yeager M, Chanock SJ, Hartge P, Rajaraman P. Personal history of diabetes, genetic susceptibility to diabetes, and risk of brain glioma: a pooled analysis of observational studies. Cancer Epidemiol Biomarkers Prev. 2014;23:47-54.
15. Cahoon EK, Inskip PD, Gridley G, Brenner AV. Immune-related conditions and subsequent risk of brain cancer in a cohort of 4.5 million male US veterans. Br J Cancer. 2014;110:1825-33.

16. Seliger C, Ricci C, Meier CR, Bodmer M, Jick SS, Bogdahn U, Hau P, Leitzmann MF. Diabetes, use of antidiabetic drugs, and the risk of glioma. Neuro Oncol. 2015. pii: nov100. [Epub ahead of print]

17. Song S, Wang B, Zhang X, Hao L, Hu X, Li Z, Sun S. Long-Term Diabetes Mellitus Is Associated with an Increased Risk of Pancreatic Cancer: A Meta-Analysis. PLoS One. 2015;10:e0134321.

18. Luo S, Li JY, Zhao LN, Yu T, Zhong W, Xia ZS, Shan TD, Ouyang H, Yang HS, Chen QK. Diabetes mellitus increases the risk of colorectal neoplasia: An updated meta-analysis. Clin Res Hepatol Gastroenterol. 2015. doi: 10.1016/j. clinre.2015.05.021.

19. Zhu Z, Wang X, Shen Z, Lu Y, Zhong S, Xu C. Risk of bladder cancer in patients with diabetes mellitus: an updated meta-analysis of 36 observational studies. BMC Cancer. 2013;13:310.

20. Chen L, Li H, Gu L, Ma X, Li X, Gao Y, Zhang Y, Shen D, Fan Y, Wang B, Bao X, Zhang X. The Impact of Diabetes Mellitus on Renal Cell Carcinoma Prognosis: A Meta-Analysis of Cohort Studies. Medicine (Baltimore). 2015;94:e1055.

21. Zhou Y, Zhang X, Gu C, Xia J. Diabetes mellitus is associated with breast cancer: systematic review, meta-analysis, and in silico reproduction. Panminerva Med. 2015;57:101-8. 